\title{
SUSCEPTIBILIDADE DAS BANANEIRAS PRATA E MYSORE AOS NEMATOIDES Radopholus similis E Helicotylenchus multicinctus * -
}

\author{
ANTONIO CARLOS ZEM **

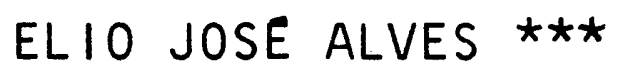

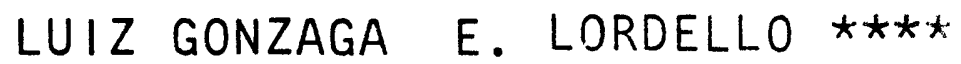

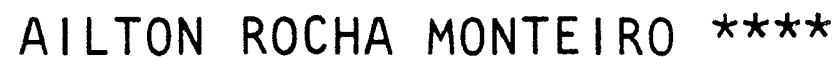

\section{RESUMO}

Os nematóides Radopholus similis e Helicoty Zenchus multicinctus são importantes inimi gos da bananicultura no Brasil e alhures.

Afim de verificar a susceptibilidade dos cultivares Prata e Mysore à infestação pelos mesmos, foram conduzidos dois experimentos de campo no Centro Nacional de Pesquisa de Mandioca e Fruticultura,em Cruz das Almas, BA.

Os dois cultivares se revelaram tolerantes aos dois nematóides, sendo a sua reprodução menor nestas bananeiras do que emplantas do

\footnotetext{
* Entregue para publicação em 23/12/81

** FMC do Brasil S/A

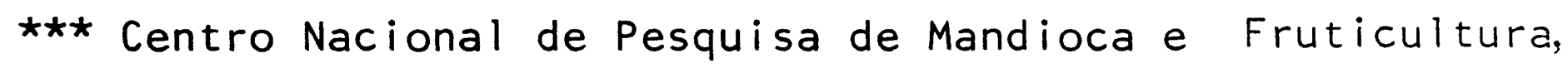
CNPMF/EMBRAPA
}

$\star \star \star \star$ Departamento de Zoologia, E.S.A. "Luiz de Queiroz", USP. 
cultivar nanicão, referido como testemunha. Prate revelou-seo pior hospedeiro.

I NTRODUÇÃO

Os nematōides Radopholus similis (Cobb, 1893) Thorne, 1949 e Helicotylenchus multicinctus (Cobb, 1893) Golden, 1956 são importantes parasitos da bananeira, com ampla distribuição nas regiões tropicais e subtropicais do mundo (SIDDIQI, 1973; WILLIAMS \& SIDDIQI, 1973; LORDELLO, 1981; O'BANNON, 1977; ZEM \& ALVES, 1981).

No Brasil, bem como alhures, a disseminação das espécies é feita principalmente através de mudas infestadas tal como, por exemplo, foi verificado na Bahia (ZEM, 1978).

A ausência do "nematōide cavernícola", R. similis, em áreas cultivadas com bananeira Prata, verificada nos levantamentos realizados por SHARMA \& SHER (1972) e ZEM (1978), para este último autor seria devida à variedade cultivada não lhe ser hospedeira ou ao plantio de mudas sadias.

Relatamos aqui duas provas de campo, realizadas no Centro Nacional de Pesquisa da Mandioca e Fruticultura (CNPMF / EMBRAPA) de Cruz das Almas, Bahia, para avaliar a susceptibilidade das bananeiras "Prata" e "Mysore" aos nematóides $R$. si milis e $H$. multicinctus.

MATERIAL E METODOS

A) 10 experimento: susceptibilidade da bananeira Prata a R. similis

Foi instalado em 22 de março de 1978, em ärea atē então não cultivada com bananeira e cujo exame nematológico não revelou a presença de $R$. similis e $H$. multicinctus.

Obedeceu ao delineamento experimental de blocos ao aca- 
so, com 4 tratamentos e 5 repetições. Cada parcela foi formada por 9 plantas, dispostas em 3 linhas de 3 plantas, no espaçamento de $1 \mathrm{~m} \times 1 \mathrm{~m}$; a linha central foi tomada como parce la útil e as laterais como bordadura.

Os tratamentos foram:

a - mudas de banana Prata sadias, não inoculadas;

b - mudas de banana Prata sadias, com inóculo de $R$. similis;

c - Mudas de Prata sadias, sem inóculo na linha central, com bordadura de banana Nanicão naturalmente infestada;

d - mudas de Nanicão naturalmente infestadas.

0 material de inóculo consistiu de raízes de bananeiras nanicão infestadas por $R$. simi $i$ s, previamente picadas e bem misturadas. Colocou-se $1 \mathrm{~kg}$ por cova, distribuindo parte no fundo e parte em mistura com o solo de enchimento.

Quatro meses após ao plantio, em 25 de julho de 1978, foram coletadas $50 \mathrm{~g}$ de raízes das 3 plantas centrais de cada parcela, à profundidade de 5 a $30 \mathrm{~cm}$, junto aos rizomas.

Em laboratório, foram tomadas sub-amostras de $10 \mathrm{~g}$. de raízes para extração e contagem dos nematóides. As raízes res tantes foram lavadas e examinadas, externa e internamente, após a secção longitudinal, para avaliar o grau de necrose, se gundo o critério seguinte:

1 - raízes sem àrea necrótica;

2 - raízes com pequenas e esporádicas lesões pardacen tas;

3 - raizes com várias lesões necróticas;

4 - raizes com intensa necrose;

5 - raizes com necrose total.

B) 20 experimento: susceptibilidade das bananeiras Prata e Mysore a R. similis e H. multicinctus em infestação mista

Foi instalado em 08/09/1978, em área cultivada com ba- 
naneira nanicão severamente infestada com Radopholus similis e $H$. multicinctus (ZEM \& ALVES, 1982). Após o arrancamento, as plantas (pseudocaules, rizomas e raízes) foram picadas e incorporadas ao solo por meio de gradagens sucessivas.

A área total foi dividida em três parcelas desiguais.

A parcela maior, medindo $1260 \mathrm{~m}^{2}$, foi plantada comocul tivar Prata, comportando 210 plantas no espaçamento de $3 \mathrm{~m} \quad \bar{x}$ $2 \mathrm{~m}$.

Outra parcela, medindo $450 \mathrm{~m}^{2}$, recebeu 72 bananeiras My sore, no referido espaçamento.

$\mathrm{Na}$ terceira parcela, foram cultivadas 32 plantas de bananeira Nanicão, também ao espaçamento de $3 \mathrm{~m} \times 2 \mathrm{~m}$, que ser viram de testemunha.

A avaliação da infestação das três bananeiras foi realizada aos 13 (01/10/1979), 19 (13/04/1980), 24 (08/09/1980), e 38 meses $(11 / 11 / 1981)$, exceto para a Nanicão, que foi destruída após os 24 meses.

As amostras de raizes foram obtidas ao acaso, de 10 plan tas de cada variedade.

A extração e contagem dos nematōides e a avaliação do grau de necrose radicular foram realizadas tal como no primei ro experimento.

Tratando-se de infestação mista, procurou-se separar os danos radiculares devidos a $R$. similis (lesões necróticas pro fundas, não punctiformes), dos causados por $H$. multicinctus (lesões punctiformes superficiais). Os resultados de tal tentativa, por causa das dificuldades inerentes, devem ser cons derados com certa reserva.

Ademais, aos 19 meses $(23 / 04 / 1981), 12$ cachos foram colhidos ao acaso em cada uma das parcelas, para se obter o peso e se contar o número de pencas e de frutos.

Observações sobre o aspecto vegetativo dos cultivares foram realizadas durante o decorrer do experimento. 


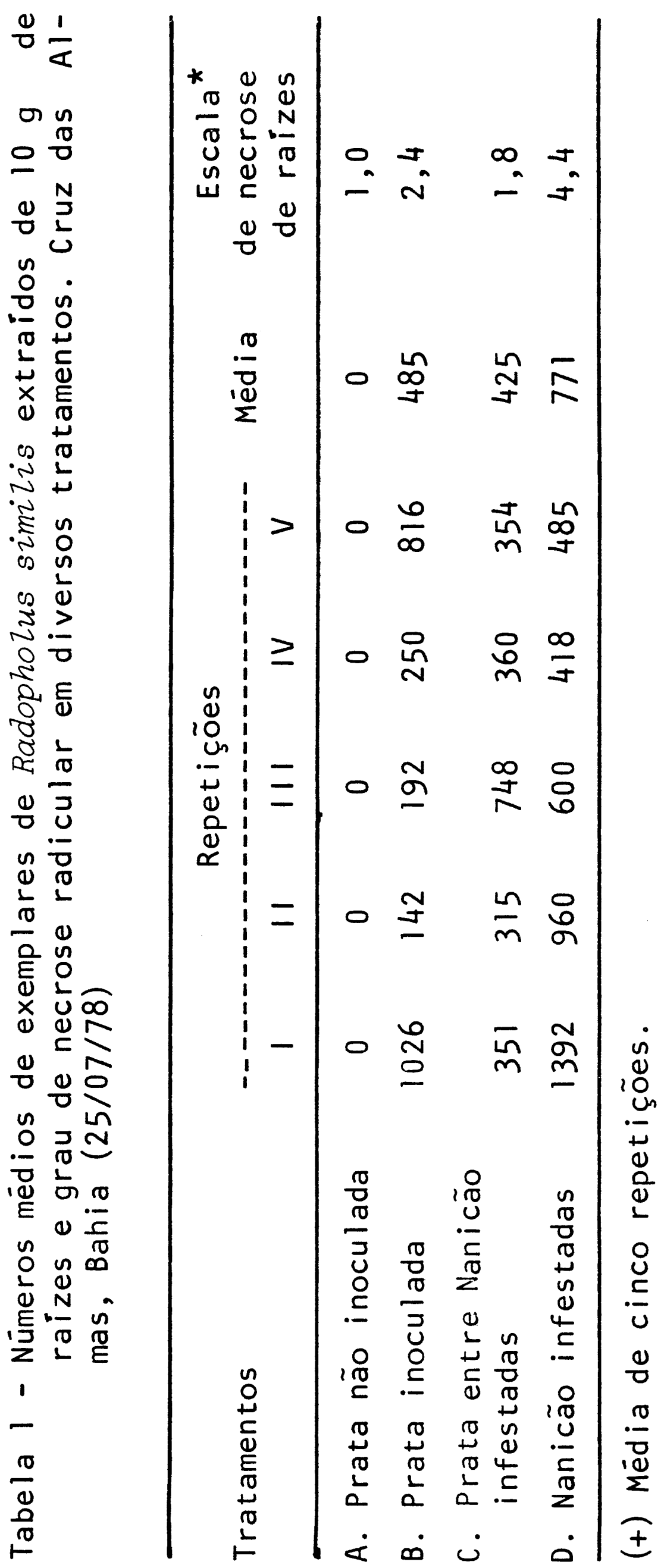




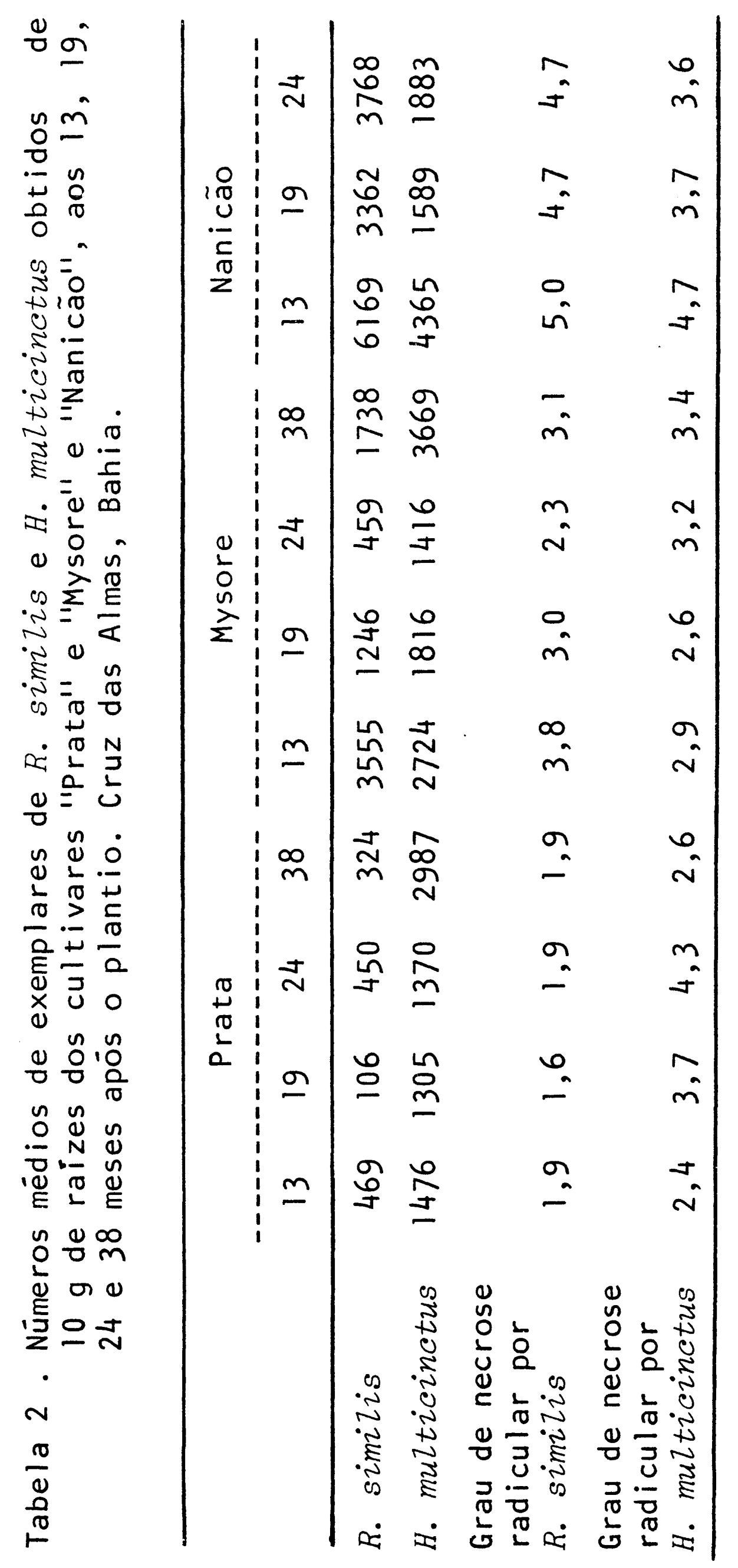




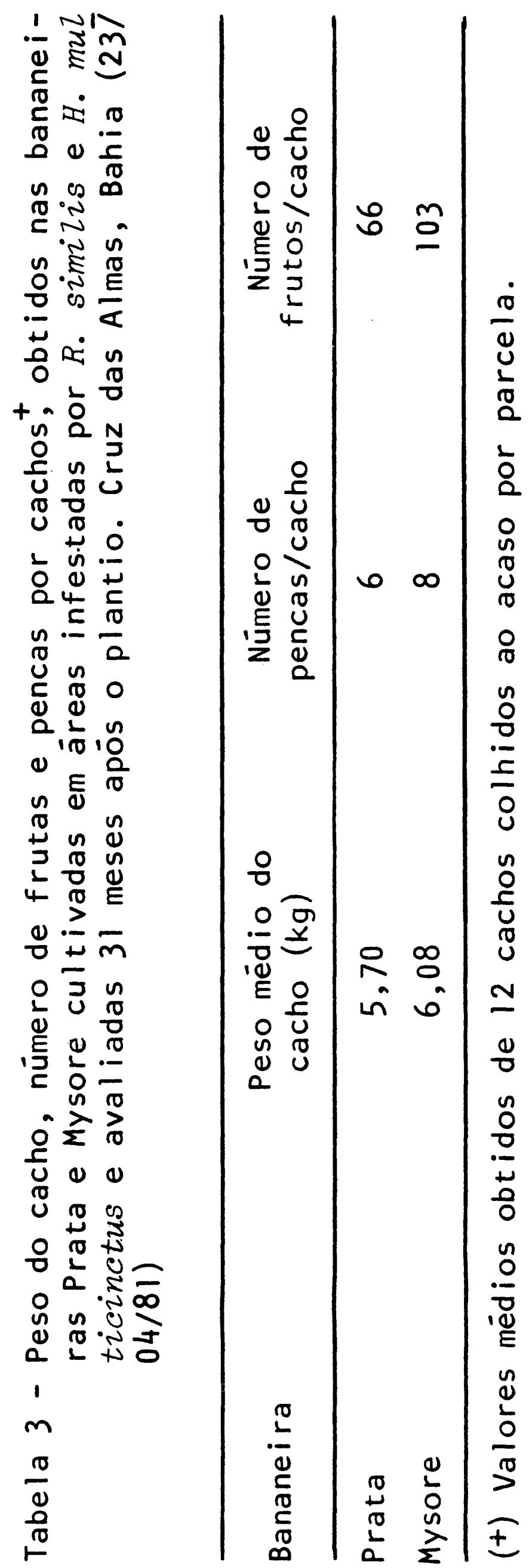


Os resultados do 1 \% experimento são apresentados na Tala 1. Os do 2\% experimento, nas Tabelas 2 e 3.

\section{a) Radopholus similis}

As três bananeiras foram parasitadas por $R$. similis, mas a Prata com indices de infestação bem menores, comportou - se como um hospedeiro menos favorăvel.

A julgar pelos indices de necrose; bem menores, a Prata foi também, menos susceptivel ao nematōide cavernícola.

A banandeira Mysore mostrou-se hospedeira mais favoräel que a Prata, e menos favorāvel que a Nanicão, ao $R$. simi is. Seus danos radiculares foram maiores que os da Prata $\bar{e}$ menores que os da nanicão, indicando susceptibilidade intermediäria.

O sistema radicular da Nanicão foi extremamente reduzi do, enquanto que os das outras bananeiras mostravam-se bem crescidos.

\section{b) Helicotylenchus multicinctus}

Os resultados do $2 \%$ experimento mostram que $H$. multicin ctus se reproduziu bem nos 3 hospedeiros, sendo que o fez meIhor na Nanicão e pior na Prata, pelo menos até os 13 meses do plantio. Nas épocas posteriores, as diferenças entre as va riedades diminuiram em decorrência de maior redução no nümeró de parasitos nas bananas nanicão e Mysore. Quanto à necrose radicular causada por $H$. multicinctus, a bananeira Nanicão ta bém se mostrou a mais sensivel até os 13 meses.

\section{c) R. similis $x H$. multicinctus}

0 cultivar Prata mostrou-se, em todas as épocas de amos 
tragem, melhor hospedeiro de H. multicinctus que de $R$. simiZis. 0 inverso ocorreu com o Nanicão. O Mysore apresentou ini cialmente maior quantidade de $R$. similis, invertendo a situa= ção nas épocas posteriores.

d) Sintomas reflexos

As bananeiras Prata e Mysore não apresentaram os sintomas de menor crescimento e clorose na parte aérea exibidos pela Nanicão. Esta pouco produziu até os 24 meses, enquanto aquelas tiveram produções aparentemente normais. Entretanto, deve-se acrescentar que a produção da bananeira Prata obtida no 2. experimento, foi um pouco menor que as obtidas no "Sistema de Produção", recentemente publicado (EMBRAPA, 1980).

\section{CONCLUSס̃ES}

Pelos resultados obtidos, podemos concluir que as bananeiras Prata e Mysore são hospedeiros tolerantes dos nematōi des Radopholus similis e Helicotylenchus multicinctus. A re= produção dos nematóides é menor nessas bananeiras do que na vạ riedade Nanicão. A Prata revelou-se o pior hospedeiro.

\section{SUMMARY}

REACTIONS OF TWO BANANA CULTIVARS TO THE NEMATODES Radopholus similis AND Helicotylenchus multicinctus

Two field trials were performed at the Centro Nacional de Pesquisa de Mandioca e Fruticultura (Cruz das Almas, Ba), to study the susceptibility of two banana cultivars (Prata and Mysore) to the nematodes Radopholus similis and Helicotylen chus multicinctus.

Both cultivars showed to be tolerant hosts to both nematodes, their reproduction being lower in these banana plants than in Nanicão cultivar. Prata was a host worst than Mysore. Nanicão is referred to as a check cultivar. 
LITERATURA CITADA

EMBRAPA, 1980. Relatório técnico anual do Centro Nacional de Pesquisa de Mandioca e Fruticultura, 1979, Brasilia, EMBRA PA/DID, 183P.

LORDELLO, L.G.E., 1981. Nematóides das plantas cultivadas, 6a ed., São Paulo, Nobel, 320pp.

O'BANNON, J., 1977. Worldwide dissemination of Radopholus similis and its importance in crop production. Jour. of $\mathrm{Ne}-$ matology 9: 16-25.

SIDDIQI, M.R., 1973. Helicotylenchus milticinctus, C.I.H. Des criptions of plant-parasitic nematodes, Set 2, n? 23 , 3pp.

WILLIAMS, K.J.0.; SIDDIQI, M.R., 1973. Radopholus simizis, C. 1.H. Descriptions of plant parasitic nematodes, Set 2, no $27,4 p p$.

ZEM, A.C.; ALVES, E.J., 1981. Observações sobre perdas provocadas por nematōides em bananeira "Nanicão" (Musa acuminata Simm. \& Shep.) (em impressão). 